\title{
Effects of Electromagnetic Fields over DNA of Hamsters with Implanted Graffi Tumor
}

\author{
Ignat Ignatov $^{1^{*}} \quad$ Christos Drossinakis $^{2} \quad$ Reneta Toshkova $^{3}$ \\ Elisaveta Zvetkova $^{4} \quad$ Iliana Yaneva $^{5} \quad$ Georgi Gluhchev $^{6}$
}

1. DSc, Professor, Scientific Research Center of Medical Biophysics (SRCMB),

Office: Bulgarian Academy of Sciences, Tsarigradsko shosse blvd, bl. 2. Sofia, Bulgaria

2. Dr. h.c, Professor, IAWG - INTERNATIONALE Akademie für Wissenschaftliche Geistheilung,

Königsteiner Str. 61 a, 65929 Frankfurt Höchst, Germany

3. PhD, MD Professor, Bulgarian Society of Biorhology, IM-BAS, Acad. G. Bonchev Street, bl. 4, Sofia 1113, Bulgaria

4. $\mathrm{PhD}, \mathrm{MD}$ Assoc. Professor, Institute of Experimental Morphology, Pathology and Anthropology with Museum, Bulgarian Academy of Science (BAS), Acad. G. Bonchev Street, bl. 25, Sofia 1113, Bulgaria 5. MD, Assoc. Professor, National Center of Public Health and Analyses, Ministry of Health, Bulgaria 6. PhD, Assoc. Professor; Institute of Information and Communication Technologies,

Bulgarian Academy of Science (BAS), Acad. G. Bonchev Street, bl. 2, Sofia 1113, Bulgaria

\begin{abstract}
Studies were conducted with model systems of bio influence (Drossinakis' method) with electromagnetic (e.m.) fields and infrared thermal field (ITF) (Ignatov, Mosin, Niggli, Drossinakis, 2013). The purpose of research is to analyze effects over DNA. Analysis of effects over water and physiological saline is carried out in the report. Results are achieved with blood serum of hamsters and physiological processes in hamsters with tumors. The water analyses have been conducted with Nonequilibrium Energy Spectrum (NES) and Differential Nonequilibrium Energy Spectrum (DNES) methods (Antonov, 1992; Ignatov, 1998). Experiments were carried out about the influence on tumor cells of mice in water. Reduction of DNES spectrum according to the control sample of cells in healthy animals was observed. (Antonov, 1992). Reduction is also observed in DNES spectrum in blood serum of people having oncological diseases, compared to the one of healthy people (Ignatov, 2012). Such a reduction is most prevalent in $\left(-0.1387 \mathrm{eV} ; 8.95 \mu \mathrm{m} ; 1117 \mathrm{~cm}^{-1}\right)$. In research of the effects of e.m. fields in water and blood serum from hamsters the range is $(-0.08--0.14 \mathrm{eV})(8.9-15.5 \mu \mathrm{m})\left(645-1129 \mathrm{~cm}^{-1}\right)$. Research is conducted for the effects over Graffi tumor that was implanted in hamsters (Toshkova, Ignatov, Zvetkova, Ignatov, Gluhchev, Drossinakis, 2019). Studies are conducted with $\mathrm{pH}$ and oxidation redox potential (ORP) effects of e.m. fields over physiological saline (Gluhchev, Ignatov, Drossinakis, 2019).
\end{abstract}

Keywords: Infrared thermal field (ITF), electromagnetic fields (e.m. fields), experimental Graffi solid tumor, energy spectrum, NES and DNES methods.

DOI: $10.7176 / \mathrm{JHMN} / 68-05$

Publication date: November $30^{\text {th }} 2019$

\section{Introduction}

In conducted studies with blood serum from animals and humans parameters of electromagnetic hydrogen bonds were analyzed. The hydrogen bonds are electromagnetic among bipolar molecules, where the hydrogen is connected to an atom with large electronegativity, such as nitrogen $(\mathrm{N})$ and oxygen $(\mathrm{O})$. Hydrogen bonds in DNA are shown in Fig. 1a. In Fig. 1b donor-acceptor interaction is presented. Hydrogen bonds in water are shown in Fig. 1c.

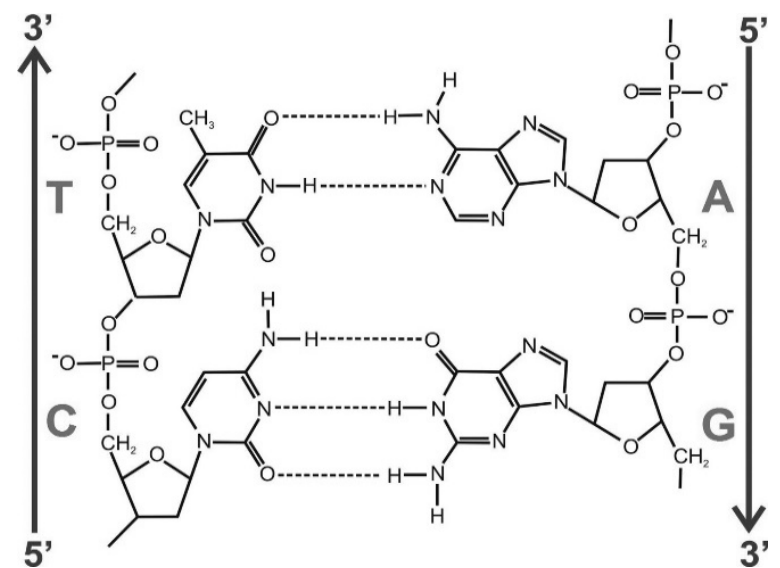

Figure 1a Hydrogen bonds among $\mathrm{H}$ and $\mathrm{N}$ or $\mathrm{O}$ in DNA 


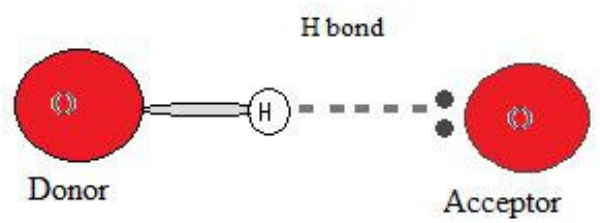

Figure 1b Donor-acceptor interaction of hydrogen bonds among $\mathrm{H}$ and $\mathrm{N}, \mathrm{F}$ or $\mathrm{O}$

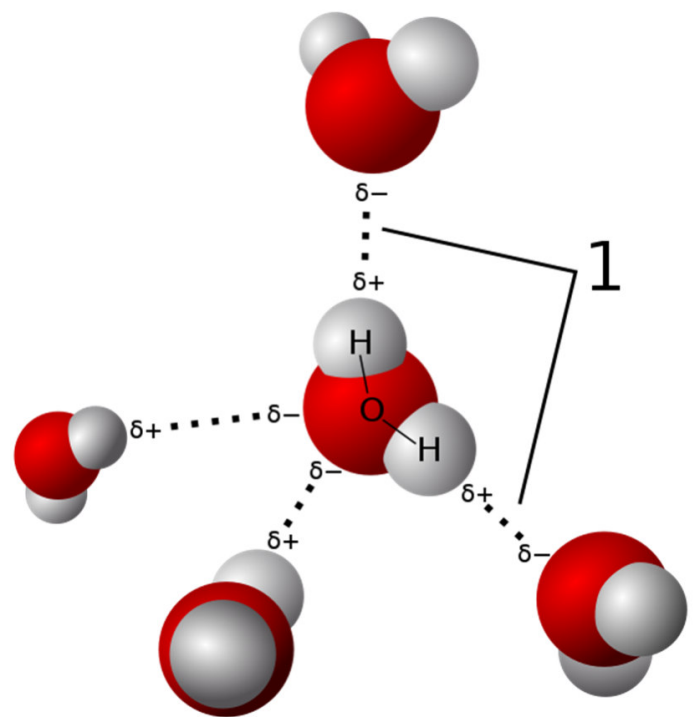

Figure 1c Hydrogen bonds among water molecules

The water is a medium of all life processes. The molecules of DNA in the cells are in the form of double helix. The pentose phosphate skeleton of both chains is placed outwards, and the nitrogenous bases are pointed towards the inside of the spiral, and are connected to each other with weak hydrogen bonds.

The multiple, although weak hydrogen bonds, provide stability to the molecule of DNA. The oxygen and nitrogen are electronegative atoms in the nitrogenous bases. Each separate nucleotide contains phosphate, deoxyribose saccharide as well as one of the four nitrogenous bases separated into two categories - purine and pyrimidine. The purine bases adenine $(\mathrm{A})$ and guanine $(\mathrm{G})$ are larger and contain two aromatic rings. The pyrimidine bases are cytosine $(\mathrm{C})$ and thymine $(\mathrm{T})$. Research shows that the range of e.m. interaction of hydrogen bonds in DNA varies from 1 to $10 \mathrm{THz}\left(10^{12} \mathrm{~Hz}\right)(30-300 \mu \mathrm{m})\left(33.4-333.6 \mathrm{~cm}^{-1}\right)$ (Tang et al., 2018). Studies of the DNA changes in neoplastic diseases are conducted in such a range (Calvin et al., 2012). The authors investigate within the range 21 до $37 \mathrm{THz}(8.9-15.5 \mu \mathrm{m})\left(645-1129 \mathrm{~cm}^{-1}\right)$ of effects over cancer cells, as the radiation of e.m. waves is in such a range (Ignatov, Mosin, Niggli, Drossinakis, 2013).

During the research with physiological saline the change of $\mathrm{pH}$ and oxidation-reduction potential (ORP) has been examined.

During the influence with e.m. waves is researched the survival rate of hamsters with tumors, as well as the change in tumor size. The DNA damage contributes to ageing and cancer, as the result depends on the type and number of lesions (injury) in DNA. The cancer related diseases are one of the main reasons for changes in DNA (Hoeijmakers, 2009). During the influence with e.m. fields change of erythrocytes and the animal hair of hamsters is observed. (Toshkova, Ignatov, Zvetkova, Gluhchev, Drossinakis, 2019).

\section{Materials and methods}

\subsection{Experimental animals}

Hamsters, breed "Golden Syrian", aged 2-4 months with weight around 90-100 g were used in the trials. The animals were grown in standard conditions in individual plastic cages with free access to food and water.

\subsection{Experimental tumor model}

Tumor cells $\left(1-2.10^{6}\right)$ from the experimental Graffi solid tumor are transplanted subcutaneously in the back of hamsters. Between days 7 and 15 after the transplantation tumor appears, grows progressively and the hamsters die around 30-35 days. In this tumor model 100\% tumor transplantation and 100\% mortality are observed. No spontaneous tumor's regression takes place. (Toshkova, 1995). 


\subsection{Influence by electromagnetic and infrared thermal fields}

This type of influence is delivered by Christos Drossinakis who holds the hamsters in the hands for a couple of minutes (Fig. 2)
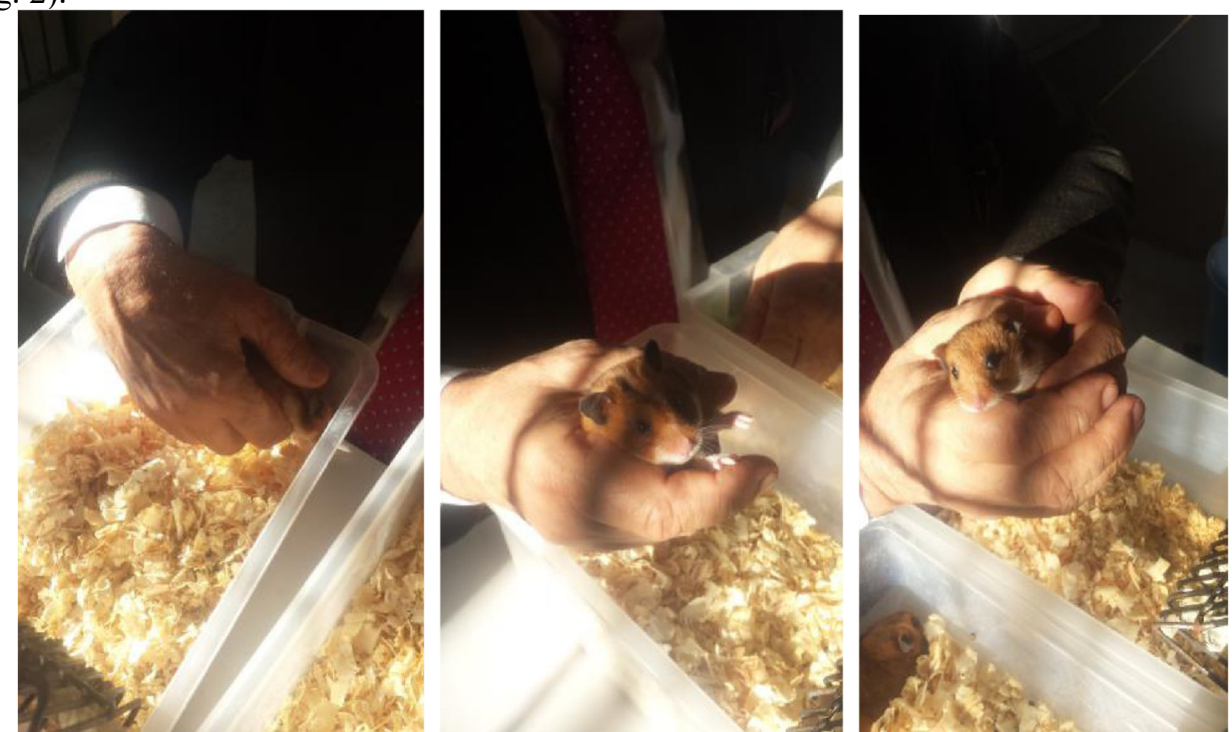

Figure 2. Bioinfluence with Infrared Thermal Field and e.m. waves on hamsters with experimental tumor

\subsection{Hematology examination}

Blood smears from experimental Graffi tumour-bearing and control hamsters are prepared, stained by MayGruenwald Giemsa method and examined light-microscopically.

\subsection{Ethical aspects}

All experiments were conducted in accordance with the European convention for protection of vertebrate animals, used for experimental and other scientific purposes (OJ L 222) and approved from the National Veterinary Medical Office.

\subsection{NES and DNES Spectral Analyses}

The device for DNES spectral analysis based on an optical principle was designed by A. Antonov. For this, a hermetic camera for evaporation of water drops under stable temperature $\left(+22-24{ }^{\circ} \mathrm{C}\right)$ conditions was used. The water drops were placed on a water-proof transparent pad, which consisted of thin maylar folio and a glass plate. The light was monochromatic with filter for yellow color with wavelength at $\lambda=580 \pm 7 \mathrm{~nm}$. The device measures the angle of evaporation of water drops from $72.3^{0}$ to $0^{0}$. The DNES-spectrum was measured in the range of $-0.08-$ $-0.1387 \mathrm{eV}$ or $\lambda=8.9-13.8 \mu \mathrm{m}$ using a specially designed computer program. The main estimation criterion in these studies was the average energy $\left(\Delta \mathrm{E}_{\mathrm{H} \ldots \mathrm{O}}\right)$ of hydrogen $\mathrm{O}$...H-bonds between $\mathrm{H}_{2} \mathrm{O}$ molecules in water samples and hamster serum blood.

\section{Results}

\subsection{Influence of e.m. waves over hydrogen bonds in water medium. Hydrogen bonds in DNA}

In the Fig. 3 the four monomers building DNA - deoxyadenosine, deoxycytidine, deoxyguanosine, deoxythymidine are presented. The hydrogen bonds are marked with arrows. DNA is located in water medium, and effects of e.m. fields over hydrogen bonds oxygen-hydrogen were being investigated. 
<smiles>[R]n1cnc2c(NCC)[n+](C)cnc21</smiles>

(Deoxy)Adenosine<smiles>[R]n1cnc2c(=O)n([CH]C)c(NC)nc21</smiles>

(Deoxy)Guanosine

Figure 19.6 Principles of Biochemistry,4/e<smiles></smiles>

(Deoxy)Cytidine<smiles>[R]n1cc(C)c(=O)n([14CH2]C)c1=O</smiles>

(Deoxy)Thymidine

Figure 3. Four monomers, which are created DNA - deoxyadenosine, deoxycytidine, deoxyguanosine, deoxythymidine

\subsection{Results with $\mathrm{pH}$ and $\mathrm{ORP}$}

In order to assess the bio-influence over blood is used physiological saline is used compatible with the human blood, consisting of $0.9 \%$ solution of $\mathrm{NaCl}$. Before the experiment $50 \mathrm{ml}$ from the solution that will perform the role of a control sample are taken from a bottle of 0.51 . The bottle with the remaining $450 \mathrm{ml}$ is held from the operator for a time period of 20 minutes. The parameters pH, ORP (Oxidation Reduction Potential) and electric conductivity in milliamperes are measured for the control sample and the treated solution. The achieved results are presented in the following Table 1

\begin{tabular}{|l|c|c|}
\hline & $\mathrm{pH}$ & ORP $(\mathrm{mV})$ \\
\hline Control Sample & 6.96 & 150 \\
\hline Sample with e.m. waves & 6.25 & 150 \\
\hline
\end{tabular}

They show that:

1. There is a decrease of $0.71 \mathrm{pH}$ of the sample compared to the control one.

2. No difference is reported in the values of ORP.

Findings

1. During the study of physiological saline 5-times increase of hydrogen ions and a change in conductivity is observed. It is a proof for recovery of the ion balance. In the healthy cells the potential for transmission of hydrogen ions $\mathrm{H}^{+}$through the membrane is $(-140 \mathrm{mV})$, and in the cancer cells it is $(-70 \mathrm{mV})$ (Alberts et al., 1994). The tendency is towards the potential recovery when influencing with ITF and e.m. waves.

2, The achieved results in hamsters with experimental tumor and physiological saline present biophysical, biochemical, biological effects of influence with ITF and e.m. waves. The processes of improvement of ion exchange and electrical potential in the cells, of the anaemic syndrome, and the synthesis of basic proteins, support the body protection and the immune status, and they hold up the tumor process.

\section{3 . Electromagnetic parameters with DNES method during influence with electromagnetic fields over} blood serum of hamsters with tumor

Table 2 shows the results from the influence of e.m. fields over distribution by energies of hydrogen bonds in $1 \%$ solution of blood serum.

\begin{tabular}{|c|c|c|c|c|c|c|c|c|c|}
\hline DNES spectrum* & & & & & & & & & \\
\hline $\begin{array}{c}\text {-E (eV) } \\
\text { X-axis }\end{array}$ & 0.0962 & 0.0987 & 0.1012 & 0.1037 & 0.1062 & 0.1087 & 0.1112 & 0.1137 & 0.1162 \\
\hline $\begin{array}{c}\left.\text { df(eV }{ }^{-1}\right) \\
\text { y-axis }\end{array}$ & $\mathbf{0}$ & $\mathbf{- 4 2 . 1}$ & $\mathbf{0}$ & $\mathbf{0}$ & $\mathbf{0}$ & $\mathbf{0}$ & $\mathbf{0}$ & $\mathbf{- 1 5 . 2}$ & $\mathbf{0}$ \\
\hline $\begin{array}{c}-\mathrm{E}(\mathrm{eV}) \\
\text { X-axis }\end{array}$ & 0.1187 & 0.1212 & 0.1237 & 0.1262 & 0.1287 & 0.1312 & 0.1337 & 0.1362 & 0.1387 \\
\hline $\begin{array}{c}\text { df(eV } \\
\text { y-axis }\end{array}$ & $\mathbf{0}$ & $\mathbf{4 3 . 6}$ & $\mathbf{- 4 2 . 1}$ & $\mathbf{0}$ & $\mathbf{2 8 . 6}$ & $\mathbf{- 1 3 . 5}$ & $\mathbf{- 1 3 . 5}$ & $\mathbf{- 1 3 . 5}$ & $\mathbf{7 2 . 2 .}$ \\
\hline
\end{tabular}

Table 2. DNES spectrum is measured in $\mathrm{eV}$ for (-E) of $1 \%$ solution of blood serum of hamsters with tumors 
with influence of e.m. fields, and control group of hamsters with tumors. The function of distribution by energies is $\mathrm{df}(\mathrm{E})$ in $\mathrm{eV}^{-1}$ for DNES spectrum.

The results show that at $8.95 \mu \mathrm{m}$ the difference in the function of distribution by energies $\mathrm{f}(\mathrm{E})$ in $\mathrm{eV}^{-1}$ for blood serum of hamsters with tumor compared to blood serum of healthy hamsters is highest. Decrease in the energy of hydrogen bonds in tumor diseases is observed at $8.95 \mu \mathrm{m}$.

\subsection{Energy of hydrogen bonds}

The average energy $\left(\mathrm{E}_{\mathrm{H} \ldots \mathrm{O}}\right)$ of hydrogen $\mathrm{H}$... O-bonds among individual $\mathrm{H}_{2} \mathrm{O}$ molecules in $1 \%$ solution of Sample of blood serum of hamsters with cancer after influence of Drossinakis is measured at $\mathrm{E}=-0.1285 \mathrm{eV}$. The result for the Control sample in $1 \%$ solution of blood serum of hamsters with cancer is $E=-0.1214 \mathrm{eV}$. The results obtained with the NES method are recalculated with the DNES method as a difference of the NES (Sample) minus the NES (Control Sample ) equalled the DNES spectrum of $1 \%$ solution of blood serum from hamsters with cancer.

\section{$\Delta \mathbf{f}(\mathbf{E})=\mathbf{f}($ sample 1$)-\mathbf{f}($ control sample 3$)$}

Thus, the result for $1 \%$ solution of blood serum from hamster recalculated with the DNES method is $\Delta E=-$ $0.0071 \pm 0.0011 \mathrm{eV}$. The result shows the increasing of the values of the energy of hydrogen bonds in $1 \%$ solution of blood serum of hamsters with tumore after influence of Drossinakis regarding control sample blood serum of hamsters with tumors.

Fig. 4 displays DNES spectrum of $1 \%$ solution of blood serum of hamsters with tumors with influence from e.m. fields, and control group of hamsters with tumors. At the x-axis are reported the values of energy (-E) of hydrogen bonds. A portion of these bonds is in DNA. The function of distribution by energies for DNES df (E) в $\mathrm{eV}^{-1}$ is given at the $\mathrm{y}$-axis. The positive values of the spectrum indicate effects over the tumor cells. Biological studies reveal improvement of the life status of tumor cells compared to the condition of healthy ones. It comes as a result of the improved replication of DNA.

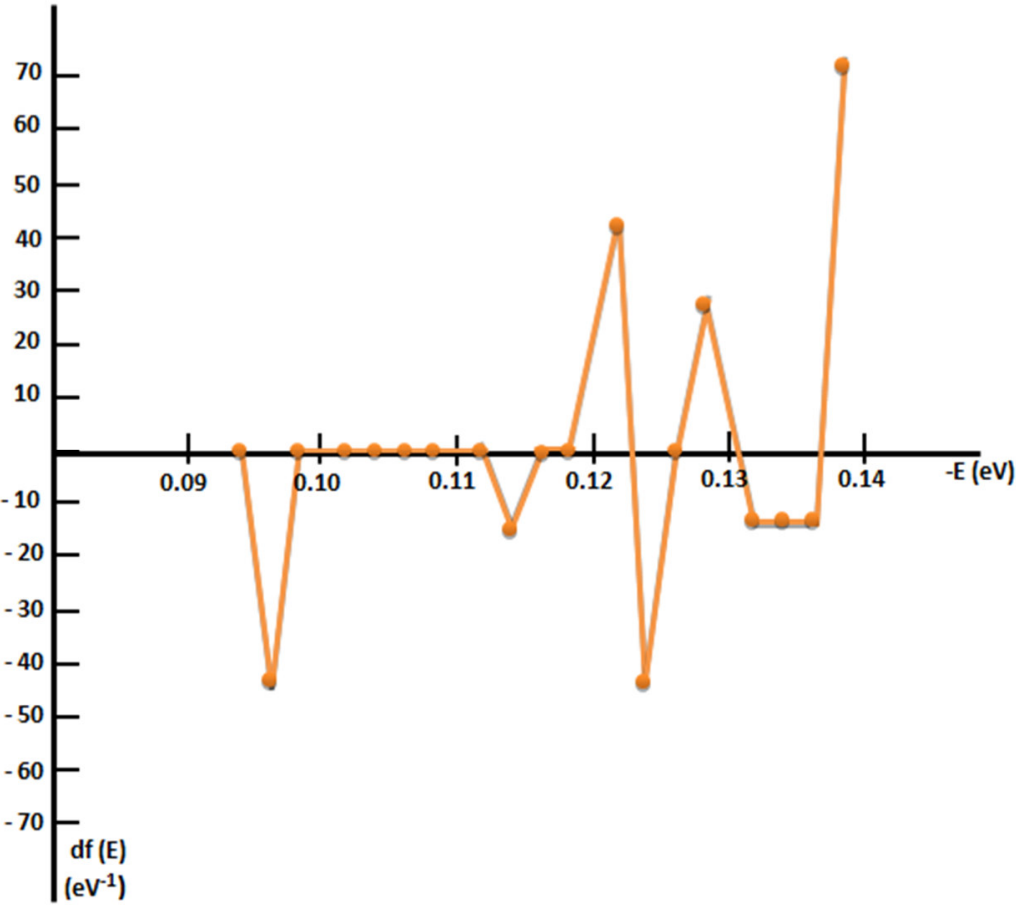

Figure 4. DNES of $1 \%$ solution of blood serum of hamsters with tumors with influence of e.m. fields as difference from the control group of hamsters with tumors.

\subsection{Biological parameters}

Following biometric parameters have been measured for the evaluation of bioinfluence on the tumor: transplantability, tumor size $(\mathrm{mm})$, lethality/mortality rate and survival rate. Their measurement revealed significant differences between the experimental and control group.

\subsubsection{Life span of hamsters}

Hamsters that have undergone bioinfluence have had low mortality. Until the 35 th day, mortality was 0 , at day $40-40 \%$, at day 45 was $80 \%$, and at day 50 it was $100 \%$. At the same time the lethality was $50 \%$ on the $30^{\text {th }}$ day and reached $100 \%$ on the $38^{\text {th }}$ day in the control group. Thus the average survival rate of hamsters with therapy was 43.6 \pm 5.8 days and for control group-without therapy $-31.75 \pm 6.8$ days, which was 12 days longer than the controls. 
Also, some delay in tumor transplantability and growth was registered. The conclusion we can draw from the obtained results is that bioinfluence therapy (in this scheme of application and duration) in hamsters with developed tumor doesn't stop the tumor growth, but delayed its progression, decreased lethality and prolonged average survival time.

\subsubsection{Hematological research}

Cytological differences in the erythrocyte /RBCs-/ morphology and differentiation were noticed in the blood smears of hamsters from control group vs bio-influenced hamsters with implanted myeloid tumours of Graffi. The observed differences probably indicate positive effects of the near infrared bio-influence on the erythropoiesis of Graffi tumour-bearing hamsters, that may lead to improvement of the anemia-syndrome - obligatory developed in this and/or in other experimental models of myeloid malignancies.

\section{Conclusion}

The results achieved from the tests within 5 days course of ITF and e.m. waves treatment of hamsters with experimental subcutaneous tumor are positive. Prolonged survival rate and decreased mortality between the experimental and control group, as well as lowered transplantability and slowed tumor growth were observed. The present results are the base for conducting further tests that aim to establish the optimum regimen of bioinfluence with regards to frequency and duration of the therapeutic procedures,

The mathematical model of blood serum solution of hamsters with cancer after the Drossinakis' influence gives significant information about the possible number of hydrogen bonds as a percent of $\mathrm{H}_{2} \mathrm{O}$ molecules with different distribution of energy relative to the same number in the two control groups.

As a result of different energies of hydrogen bonds, the surface tension of the blood serum solution of cancer hamsters is increased after the treatment relative to the control samples- This effect is connected with the preservation and increase in the energy of the biochemical processes between water molecules and biomolecules.

The achieved results of hamsters from experimental bio-influence of Christos Drossinakis reveal their biological efficiency and can be subject of future studies. Extending the life of the hamsters is an indicator of improving immune status. The obtained results correspond to recent data from the medical scientific literature for the positive effect of the near infrared irradiation on the structure and function of erythrocyte membrane in normal and pathological conditions. The mitochondrial polarity in cancer cells was found to be lower than that of normal cells. Drossinakis is increasing the mitochondrial polarity.

The basic conclusion is that Drossinakis is able to increase the average energy of hydrogen bonds among water molecules in the blood of hamsters with cancer after treatment compared to the average energy of hydrogen bonds among water molecules in the blood of non-treated hamsters as control group.

In the report there are results with DNA, DNES spectrum of $1 \%$ solution of blood serum of hamsters with tumors with influence from e.m. fields, and control group of hamsters with tumors. At the x-axis of Fig. 4 the values of energy (-E) of hydrogen bonds are reported. A portion of these bonds is in DNA. The function of distribution by energies for DNES df $(E)$ в in $\mathrm{eV}^{-1}$ is given at the y-axis. The positive values of the spectrum indicate effects over the tumor cells. Biological studies reveal improvement of the life status of tumor cells compared to the condition of healthy ones. It comes as a result of the improved replication of DNA. After the influence the hydrogen bonds among oxygen $(\mathrm{O})$ and hydrogen $(\mathrm{H})$ in DNA helix have bigger energy.

During the study of physiological saline 5-times increase of hydrogen ions and a change in conductivity is observed. It is a proof for recovery of the ion balance. In the healthy cells the potential for transmission of hydrogen ions $\mathrm{H}^{+}$through the membrane is $(-140 \mathrm{mV})$, and in the cancer cells it is $(-70 \mathrm{mV})$. The increase of the number of hydrogen ions reveals a process of recovery in the potential of a cancer cell to a healthy condition.

The effect of bioinfluence of Christos Drossinakis over the values of $\mathrm{pH}$ of physiological saline can be considered as established.

Due to the $65 \%$ of water content in the human body, it can be considered that its parameters irrespective of its consistency in the blood and internal organs, will be influenced from an external bioinfluence, which will affect their functioning, and hence the health condition of the body.

The potential of hydrogen ions in a healthy cell is $(-140 \mathrm{mV})$, and in a cancer cell $(-70 \mathrm{mV})$. The increase of the number of hydrogen ions reveals a process of recovery in the potential of a cancer cell to a healthy condition.

\section{References}

Alberts, B. et al.: (1994) Molecular Biology of the Cell $3^{\text {rd }}$ ed.., Garland Publishing, New York and London.

Antonov, A. Galabova, T. (1992) Ext. Abstr. Of the $6^{\text {th }}$ National Conference of Biomedical Physics and Engeneering, 60.

Antonov, A., Galabova, T., Todorova, L.\&Tomov, (1993) Observatoire de Montagne de Mussala OM2, Edit par J.P. Carbonel and J. N. Stamenov, Sofia, 113.

Antonov, A. (1995) Research of the Non-equilibrium Processes in the Area in Allocated Systems. Dissertation thesis for degree "Doctor of physical sciences", Blagoevgrad, Sofia. 
Azab B. et al. (2013) Pretreatment Neurophil/lymphocyte Ratio is Superior to Platelet/lymphocyte Ratio as a Predictor of Long-term Mortality in Breast Cancer Patients, Med. Oncol., 30, 432

Calvin, Yu. et al. (2012) The Potential of Terahertz Imaging for Cancer Diagnosis. A Review of Investigations to Date.

Drossinakis, Ch., Toshkova, R., Zvetkova, E, Ignatov, I, \&Gluhchev, G. (2019) Methods of Research in Vivo Research of Therapeutical Effect in Hamsters with Experimental Myeloid Tum or of Graffi, 8th World Congress on Immunology, Pulsus, London, 3, 21.

Drossinakis, Ch., Ignatov, I., Toshkova, R., Zvetkova, E.\& Gluhchev, G. (2019) Functional Changes of Cells and DNA by Electromagnetic Waves in the Case of Cancer, Cancer Stem Cell, Epidemiology and Surgery, Seoul, 23

Drossinakis, Ch., Toshkova, R., Zvetkova, E., Ignatov, I.\& Gluhchev, G. (2019) Methods of Research in Vivo Research of Therapeutical Effect in Hamsters with Experimental Mieloid Tumor of Graffi, Journal of Nursing Research and Practice, 1-2.

Tang et al. (2018) Detection of DNA Oligonucleotides with Base Mutations by Terahertz Spectroscopy and Microstructures, PLoS ONE, 13 (1): e0191515.

Gluhchev, G., Ignatov, I., Karadzhov, S., Miloshev, G., Ivanov, N.\& Mosin, O.V. (2015) Electrochemically Activited Water. Biophysical and Biological Effects of Anolyte and Catholyte as Types of Water, Journal of Medicine, Physiology and Biophysics, 10, 1-17.

Ignatov, A., Antonov, A.\& Galabova, T. (1998) Medical Biophysics - Biophysical Fields of Man, Gea Libris, Sofia.

Hoeijmakers, J.H. (2009) DNA Damage, Aging, and Cancer, 361(15):1475-85.

Ignatov, I., Mosin, O. V. (2013) Structural Mathematical Models Describing Water Clusters, Journal of Mathematical Theory and Modeling, 3 (11), 72-87.

Ignatov, I., Mosin, O. V., Niggli, H. \&Drossinakis, Ch. (2014) Evaluating of Possible Methods and Approaches for Registering of Electromagnetic Waves Emitted from the Human Body, Advances in Physics Theories and Applications, 30, 15-33.

Ignatov, I., Toshkova, R., Gluhchev, G.\& Drossinakis, Ch. (2019) Results of Blood Serum from Cancer Treated Hamsters with Infrared Thermal Field and Electromagnetic Fields, Journal of Health, Medicine and Nursing, 58: $101-112$.

Ignatov, I. (2011) Entropy and Time in Living Organisms, Euromedica, Hanover, pp. 60-62.

Ignatov I., Mosin O.V. (2013) Possible Processes for Origin of Life and Living Matter with modeling of Physiological Processes of Bacterium Bacillus Subtilis in Heavy Water as Model System, Journal of Natural Sciences Research, 3 (9): 65-76

Ignatov, I. \&Mosin, O. V. (2013) Modeling of Possible Processes for Origin of Life and Living Matter in Hot Mineral and Seawater with Deuterium, Journal of Environment and Earth Science, 3 (14): 103-118. Ignatov, I.\& Mosin, O. V. (2013) Structural Mathematical Models Describing Water Clusters, Journal of Mathematical Theory and Modeling, 3 (11): 72-87.

Toshkova R. (1995) Attempts for Immunomodulation in Hamsters with Transplanted Myeloid Tumor, Previously Induced by Graffi Virus, Bulgarian Academy of Sciences, PhD Dissertation, Sofia.

Toshkova, R., Ignatov, I., Zvetkova, E. \&Gluhchev, G. (2019) Bioinfluence with Infrared Thermal and Electromagnetic Fields as a Therapeutic Approach of Hamsters with Experimental Graffi Myeloid Tumor, Journal of Natural Sciences Research, 9 (4):1-11.

Toshkova, R., Ignatov, I., Zvetkova, E., Gluhchev, G. \& Drossinakis, Ch. (2019) Beneficial Effects of Drossinakis Bio-influence (with Infrared Thermal and Electromagnetic Fields) on the Development of Experimental Graffi Myeloid Tumors in Hamsters. Hematological studies, Journal of Medicine, Physiology and Biophysics, 54, 13-17.

Toshkova, R., Ignatov, I., Zvetkova, E. \& Gluhchev, G. (2019) Effects of Catholyte Water on the Development of Experimental Graffi Tumor on Hamsters, Cells\&Cellular Life Sciences Journal, 4 (1), 000140

Toshkova, R., Ignatov, I., Zvetkova, E. \& Gluhchev, G. (2019) Effects of Catholyte Water on the Development of Experimental Graffi Tumor on Hamsters, European Journal of Medicine, 7(1): 45-56.

Zvetkova E. (2006) F.140. Quantitative Reduction in the RNP-Contents of Peripheral Blood Lymphocytes in Cancer Patients. Conference: $6^{\text {th }}$ Annual Meeting of the Federation-of-Clinical-Immunology-Societies Location: San Francisco, CA Date: JUN 07-11, Clinical Immunology,: 119:S100.

Zvetkova E., \&Fuchs, D. (2017) Medical Significance of Simultaneous Application of Red Blood Cell Distribution Width (RDW) and Neopterin as Diagnostic Biomarkers in Clinical Practice, Pteridines, 28(34):133-140. 